\title{
Highly stable, mesoporous mixed lanthanum- cerium oxides with tailored structure and reducibility
}

\author{
S. Liang, Esteban Broitman, Y. Wang, A. Cao and G. Veser
}

\section{Linköping University Post Print}

\section{¿ Tweet}

N.B.: When citing this work, cite the original article.

The original publication is available at www.springerlink.com:

S. Liang, Esteban Broitman, Y. Wang, A. Cao and G. Veser, Highly stable, mesoporous mixed lanthanum-cerium oxides with tailored structure and reducibility, 2011, Journal of Materials Science, (46), 9, 2928-2937. http://dx.doi.org/10.1007/s10853-010-5168-y

Copyright: Springer Verlag (Germany)

http://www.springerlink.com/?MUD=MP

Postprint available at: Linköping University Electronic Press

http://urn.kb.se/resolve?urn=urn:nbn:se:liu:diva-88524 


\title{
Highly stable, mesoporous mixed lanthanum-cerium oxides with tailored structure and reducibility
}

\author{
Shuang Liang ${ }^{a b}$, Esteban Broitman ${ }^{\mathrm{c}}$, Yanan Wang ${ }^{a b}$, Anmin Cao $^{a b}$ and Götz Veser $^{* a b}$ \\ Received (in $X X X, X X X) X$ th $X X X X X X X X X 200 X$, Accepted Xth $X X X X X X X X X 200 X$ \\ ${ }_{5}$ First published on the web $X$ th $X X X X X X X X X 200 X$ \\ DOI: 10.1039/b000000x
}

\begin{abstract}
Pure and mixed lanthanum and cerium oxides were synthesized via a reverse microemulsion-templated route. This approach yields highly homogeneous and phase-stable mixed oxides with high surface areas across the entire range of La:Ce ratios from pure lanthana to pure 10 ceria. Surprisingly, all mixed oxides show the fluorite crystal structure of ceria, even for lanthanum contents as high as $90 \%$. Varying the La:Ce ratio not only allows tailoring of the oxide morphology (lattice parameter, pore structure, particle size, and surface area), but also results in a fine-tuning of the reducibility of the oxide which can be explained by the creation of oxygen vacancies in the ceria lattice upon La addition. The described approach should be applicable to a

15 broad range of other mixed oxides, and hence opens the path towards functional tailoring of oxide materials, such as rational catalyst design via fine-tuning of redox activity.
\end{abstract}

\section{Introduction}

Functional materials based on rare earth elements are of broad technological interest, and the synthesis of nanostructured rare 20 earth oxides in particular, such as nanostructured lanthanum and cerium oxides, has found increasing attention in recent years. ${ }^{1-4}$ For example, nanostructured lanthana has been shown to be an outstanding absorbent for $\mathrm{H}_{2} \mathrm{~S}^{5,6}$ (a widely regulated air pollutant and a strong poison for typical metal 25 catalysts ${ }^{7,8}$ ), while ceria is widely investigated as catalyst support for noble metals in a number of reactions ${ }^{9-12}$. Beyond the pure oxides, growing interest is focusing on mixed cerium and other rare earth oxides 4, 13-15. Doped lanthana nanoparticles are of interest as chemically stable photo30 luminescent materials ${ }^{16}$, and doped ceria shows strongly improved performance as catalyst support and oxygen storage component in applications such as automotive exhaust control 4, 17-19. The latter is due to the fact that-unlike many traditional support materials-cerium oxide plays an important, active role 35 as oxygen storage and oxygen transfer material in redox reactions based on the facile conversion between $\mathrm{Ce}^{4+}$ and $\mathrm{Ce}^{3+}$ on the oxide surface. Doping ceria has been shown to further improve this performance due to increased reducibility and oxygen storage capacity. For example, computational 40 studies have shown that doping ceria with $\mathrm{Zr}$ or Th cations lowers the reduction energy and increases the oxygen mobility $^{3}$. More recent results indicate that La dopings are even more effective in favoring the $\mathrm{Ce}^{4+} / \mathrm{Ce}^{3+}$ reduction process than other trivalent dopants such as $\mathrm{Sc}, \mathrm{Mn}, \mathrm{Y}, \mathrm{Gd}$, 45 and that this effect is enhanced with increasing La content ${ }^{4}$.

Despite this interest in mixed $\mathrm{La}_{2} \mathrm{O}_{3}-\mathrm{CeO}_{2}$ in particular, the synthesis of stable, homogeneous mixed oxides still poses a major challenge. Previous studies reported phase separation of mixed $\mathrm{La}_{2} \mathrm{O}_{3}-\mathrm{CeO}_{2}$ at elevated temperature ${ }^{17,}{ }^{18}$, and the 50 solubility limit for $\mathrm{La}_{2} \mathrm{O}_{3}-\mathrm{CeO}_{2}$ solid solutions prepared by various methods is typically reported to be between $40 \%-70 \%$

$$
14,17,19-21
$$

Here, we report the synthesis of nanostructured mixed $\mathrm{La} / \mathrm{Ce}$-oxides via a straightforward reverse microemulsion55 templated approach, and the systematic investigation of the La:Ce-ratio on their reducibility. Reverse microemulsiontemplated syntheses offer exceptional control over synthesis conditions ${ }^{22,23}$. Confining the materials synthesis into the nanosized micelles not only allows regulation of particle size, 60 and hence yields high surface area materials, but it also exerts control over the hydrolysis rate of different precursors for mixed oxides and hence allows for finely controlled synthesis of highly homogeneous mixed oxides with excellent thermal stability 24, 25. Due to these well-controlled synthesis 65 conditions, we were able to synthesize homogeneous mixed $\mathrm{La} / \mathrm{Ce}$-oxides over the entire range of La:Ce-ratios. The resulting oxides are characterized by high surface areas and, more importantly, exceptional stability with no phase separation up to temperatures in excess of $1000^{\circ} \mathrm{C}$. The full 70 control of the composition furthermore enables fine tailoring of the reducibility of the materials.

\section{Experimental section}

Materials and syntheses

Chemical reagents including lanthanum isopropoxide (Alfa75 aesar, La 40\%), cerium isopropoxide (Alfa-aesar, Ce 37$45 \%$ ), poly(ethylene glycol)-block-poly(propylene glycol)block-poly(ethylene glycol) (PEPP, Aldrich, Mn=2000), isooctane (Aldrich, 99.8\%), 1-pentanol (Aldrich, 99+\%), anhydrous 2-propanol (Aldrich, 99.5\%) were used as received 80 without further purification. Pure lanthanum oxide $\left(\mathrm{La}_{2} \mathrm{O}_{3}\right)$, cerium oxide $\left(\mathrm{CeO}_{2}\right)$, and mixed lanthanum cerium oxides $\left(\mathrm{La}_{\mathrm{x}} \mathrm{Ce}_{1-\mathrm{x}} \mathrm{O}_{2-0.5 \mathrm{x}}\right)$ were all synthesized by a reverse microemulsion method, as adapted previously in our laboratory ${ }^{26,27}$. For example, to prepare $\mathrm{La}_{0.5} \mathrm{Ce}_{0.5} \mathrm{O}_{1.75}, 10.97$ $85 \mathrm{~g}$ de-ionized water, $38.57 \mathrm{~g}$ isooctane and $12.85 \mathrm{~g}$ PEPP, 150 g 1-pentanol were used to obtain a reverse microemulsion. 0.5 
g lanthanum isopropoxide and $0.59 \mathrm{~g}$ cerium isopropoxide were dissolved in $108 \mathrm{ml}$ anhydrous 2-propanol by stirring, and refluxed at $95^{\circ} \mathrm{C}$ for $2 \mathrm{~h}$. The solution was then introduced to the microemulsion at room temperature. After ageing for 72 $5 \mathrm{~h}$, the water and oil phases were separated by temperatureinduced phase separation (TIPS). The product phase was washed several times with acetone, and remaining volatile residues were removed via freeze drying. Finally, the dried powder was calcined at $450{ }^{\circ} \mathrm{C}$ or $750{ }^{\circ} \mathrm{C}$ for $2 \mathrm{~h}$ in air.

\section{${ }_{10}$ Characterization}

The specific surface area was determined via nitrogen sorption in a Micromeritics ASAP 2020 gas adsorption analyzer using the BET method. Prior to the measurement, the samples were degassed for $2 \mathrm{~h}$ at $200^{\circ} \mathrm{C}$ under high vacuum.

15 The compositions of mixed oxides were determined by Energy-dispersive $\mathrm{x}$-ray analysis (EDX) equipped on Philips XL-30 field emission scanning electron microscope (SEM). The X-ray diffraction (XRD) measurements were performed with a high-resolution powder X-ray diffractometer (Phillips $\left.{ }_{20} \mathrm{PW} 1830\right)$ in line focus mode employing $\mathrm{Cu}-\mathrm{K} \alpha$ radiation $(\lambda=$ $1.5418 \AA$ A). Crystal phases were identified based on JCPDS cards. Particle sizes were calculated from the Debye-Scherrer equation. Sample morphology was determined by transmission electron microscopy (JEOL-2000FX). ${ }_{25}$ Temperature-programmed reduction by hydrogen $\left(\mathrm{H}_{2}\right.$-TPR $)$ was conducted using a Micromeritics Chemisorb 2750 system equipped with a thermal conductivity detector. During the TPR analysis, the samples were first oxidized in $5 \% \mathrm{O}_{2} / \mathrm{He}$ at $450^{\circ} \mathrm{C}$ for $2 \mathrm{~h}$, and then TPR was performed by heating the 30 sample $(100 \mathrm{mg})$ at $5{ }^{\circ} \mathrm{C} / \mathrm{min}$ to $900{ }^{\circ} \mathrm{C}$ in a $10 \% \mathrm{H}_{2} / \mathrm{Ar}$ flow ( $30 \mathrm{ml} / \mathrm{min}$ ). A cold trap filled with aceton-dry ice mixture was placed between reactor and TCD to remove the water vapor.

X-ray photoelectron spectroscopy (XPS) spectra for 35 samples containing different La concentrations were recorded in a Theta Probe system (Thermo Scientific) using a $400 \mu \mathrm{m}$ diameter monochromatic Al- $\mathrm{K}_{\alpha}$ excitation at $1486.6 \mathrm{eV}$ with a Hemispherical Analyzer operated in the constant pass energy mode at $50 \mathrm{eV}$. To analyze the individual contributions of the ${ }_{40} \mathrm{Ce} 3 \mathrm{~d}$ and La $3 \mathrm{~d}$ core levels, peak decomposition was carried out by using mixed Gaussian-Lorentzian peaks with a Shirleytype background.

\section{Results and discussion}

\section{Pure oxides}

${ }_{45}$ Using the above described experimental approach, pure lanthanum and cerium oxides were first synthesized as reference points for the following synthesis and characterization of the mixed oxides. In particular for $\mathrm{La}_{2} \mathrm{O}_{3}$ reports of successful syntheses of high surface area materials 50 are limited to-date ${ }^{28,29}$. It seemed hence of interest in itself to investigate whether a carefully controlled microemulsionbased synthesis could result in increased surface areas.

The morphology of pure $\mathrm{La}_{2} \mathrm{O}_{3}$ as synthesized in our microemulsion method is illustrated by the TEM images in ${ }_{55}$ Figure 1 ( $\mathrm{a}$ and $\left.\mathrm{b}\right)$. The images reveal a mesoporous structure of the oxide, created by the agglomeration of dense nanoparticles about $10-20 \mathrm{~nm}$ in size. The mesoporous character of the materials is confirmed by BET, as seen in the typical type IV isotherms with $\mathrm{H} 2$ hysteresis shown in Figure ${ }_{60} 2$ (top, $a$ and b). The surface area of the lanthana is close to $100 \mathrm{~m}^{2} / \mathrm{g}$ after calcination at $450{ }^{\circ} \mathrm{C}$ (see Table 1), well in excess of previously reported surface areas of less than 30 $\mathrm{m}^{2} / \mathrm{g}^{30}, 31$. XRD shows that the sample is largely amorphous after calcination at $450{ }^{\circ} \mathrm{C}$ (Figure 2 top, c), in agreement with ${ }_{65}$ the known high crystallization temperature of $\mathrm{La}_{2} \mathrm{O}_{3}$ of $\sim 700$ ${ }^{\circ} \mathrm{C}^{5,32,33}$

Cerium oxide synthesized in the same way shows a similar morphology and structure (Figure $1 \mathrm{c}$ and $\mathrm{d}$, and Figure 2, bottom, a and b) and similarly high surface area of $\sim 80 \mathrm{~m}^{2} / \mathrm{g}$ 70 (Table 1), which can be attributed to the small particle size templated by the micelles in the microemulsion. Unlike $\mathrm{La}_{2} \mathrm{O}_{3}$, however, $\mathrm{CeO}_{2}$ is already highly crystalline after calcination at $450{ }^{\circ} \mathrm{C}$, as confirmed by XRD (Figure $2 \mathrm{c}$, bottom). It is worthwhile to note that, compared to $\mathrm{La}_{2} \mathrm{O}_{3}$, the 75 isotherm of $\mathrm{CeO}_{2}$ calcined at $450{ }^{\circ} \mathrm{C}$ (Figure 2, bottom, a,) exhibits a different type $\mathrm{H} 2$ hysteresis loop with a linear adsorption isotherm, indicating a highly disordered mesoporous structure with a wide pore size distribution ${ }^{34,35}$. After high-temperature calcination at $750{ }^{\circ} \mathrm{C}$, the hysteresis 80 loop changes to a type H1 hysteresis (Figure 2, bottom, b, ) attributed to agglomerates of spheres with roughly uniform size, resulting in narrow pore size distributions ${ }^{34}$.

Table 1 Surface area and particle size of $\mathrm{La}_{2} \mathrm{O}_{3}$ and $\mathrm{CeO}_{2}$

\begin{tabular}{ccccc}
\hline & \multicolumn{2}{c}{$450{ }^{\circ} \mathrm{C}$} & \multicolumn{2}{c}{$750^{\circ} \mathrm{C}$} \\
\cline { 2 - 5 } & $\begin{array}{c}\text { Surface } \\
\text { area }\left(\mathrm{m}^{2} / \mathrm{g}\right)\end{array}$ & $\begin{array}{c}\text { Particle } \\
\text { Size }(\mathrm{nm})\end{array}$ & $\begin{array}{c}\text { Surface } \\
\text { area }\left(\mathrm{m}^{2} / \mathrm{g}\right)\end{array}$ & $\begin{array}{c}\text { Particle } \\
\text { Size }(\mathrm{nm})\end{array}$ \\
\hline $\mathrm{La}_{2} \mathrm{O}_{3}$ & 95.5 & N.A.* & 26.5 & 45.9 \\
$\mathrm{CeO}_{2}$ & 69.5 & 10.3 & 12.8 & 22.3 \\
\hline
\end{tabular}

* $\mathrm{La}_{2} \mathrm{O}_{3}$ calcined at $450{ }^{\circ} \mathrm{C}$ is amorphous and no particle size data can be 85 acquired from XRD. TEM images in Figure 1 allow estimate of particle size in the range of $10-20 \mathrm{~nm}$.

This change in structure upon high-temperature calcination also results in a strong decrease in surface area. As shown in Table 1, both pure oxides lose more than $70 \%$ of their surface 90 area after calcination at $750{ }^{\circ} \mathrm{C}$ due to rapid growth of the primary oxide particles. This strong sintering is not surprising for lanthana, which undergoes crystallization, resulting in large mass transport and hence restructuring of the material. However, a similarly large loss in surface area for ceria is less 95 expected. It can most likely be attributed to the removal of residual surfactant that was capping the nanoparticles at lower temperature and is being burnt off in the temperature range between 450 and $500{ }^{\circ} \mathrm{C}{ }^{26}$. These cappings help to stabilize the materials at lower temperature by forming a diffusion 100 barrier around individual nanoparticles, essentially "freezing" the materials in their disordered morphology resulting from the synthesis. After this barrier is burnt off at higher calcination temperatures, the particles start to sinter and rapid particle growth occurs (as confirmed by Debye-Scherrer 105 analysis, see Table 1). This can also explain the transition in the nitrogen sorption hysteresis for ceria from an $\mathrm{H} 2$ to $\mathrm{H} 1$ hysteresis. However, despite this strong loss in surface area upon calcinations at $750{ }^{\circ} \mathrm{C}$, the surface area of both pure 
oxides compares favorably with previous reports in the literature ${ }^{30,36}$

\section{Mixed lanthanum/cerium oxides}

Based on the same microemulsion-templated synthesis used 5 for the pure oxides, mixed $\mathrm{La} / \mathrm{Ce}$-oxides were synthesized by using carefully adjusted mixtures of the respective precursors. The actual lanthanum and cerium content was determined via energy-dispersive $\mathrm{x}$-ray analysis (EDX) and was found to be in close agreement with the nominal values from the synthesis 10 (table 2). For simplicity, we therefore use the nominal fractional La content ' $x$ ' to refer to the samples with different lanthanum content throughout the present report.

Table 2 Composition of mixed $\mathrm{La} / \mathrm{Ce}$-oxides

\begin{tabular}{ccc}
\hline La nominal fraction ' $\mathrm{x}$ ' & $\begin{array}{c}\text { La actual at. \% (from } \\
\text { EDX) }\end{array}$ & $\begin{array}{c}\text { Ce actual at. \% } \\
\text { (from EDX) }\end{array}$ \\
\hline 0.1 & 11.08 & 88.92 \\
0.25 & 26.33 & 73.67 \\
0.5 & 50.78 & 49.22 \\
0.75 & 74.68 & 25.32 \\
0.9 & 85.03 & 14.97 \\
\hline
\end{tabular}

Figure 3 shows the TEM image along with the type IV 15 isotherm with type $\mathrm{H} 2$ hysteresis loop for a mixed oxide with $\mathrm{La}: \mathrm{Ce}=1: 1$ after calcination at $450{ }^{\circ} \mathrm{C}$. As expected, the mixed oxide shows no obvious difference in morphology and structure from either pure oxide.

Figure 4 (A) shows the XRD diffractograms for pure and 20 mixed $\mathrm{La}_{\mathrm{x}} \mathrm{Ce}_{1-\mathrm{x}} \mathrm{O}_{2-0.5 \mathrm{x}}$ with increasing La content from $0 \%$ (i.e. pure ceria, Figure 4 (A) (a)) to $100 \%$ (i.e. pure lanthana, Figure $4(\mathrm{~A})(\mathrm{g}))$ after calcinations at $750{ }^{\circ} \mathrm{C}$. The pure oxides show cubic and hexagonal crystalline structures for ceria and lanthana, respectively, in agreement with the standard XRD 25 patterns of $\mathrm{CeO}_{2}$ (JCPDS 34-0394) and $\mathrm{La}_{2} \mathrm{O}_{3}$ (JCPDS $05-$ 0602). Surprisingly, however, all mixed oxides display only the (shifted) fluorite pattern of ceria (Figure 4 (A) (b)-(f)), even for La loadings as high as $90 \%$. No second phases or additional reflections can be found for any mixed oxide, 30 indicating the formation of a single, homogeneous mixedoxide phase. With increasing La content, however, one observes an increasing shift in the diffraction pattern, corresponding to a continuous change in the lattice parameter, as well as a broadening of the $\mathrm{La}_{\mathrm{x}} \mathrm{Ce}_{1-\mathrm{x}} \mathrm{O}_{2-0.5 \mathrm{x}}$ reflections, 35 indicating a decrease in particle size.

These trends are quantified in Figure 4 (B), which shows the change of lattice constant and particle diameter as function of La content as calculated from the XRD patterns. One can see a continuous decrease in particle diameter with increasing $40 \mathrm{La}$ content, from $\sim 22 \mathrm{~nm}$ for pure ceria to $\sim 7 \mathrm{~nm}$ for $90 \% \mathrm{La}$ content. This indicates that the addition of lanthanum suppresses the crystal growth of ceria, as previously observed by Wang et al. ${ }^{6}$.

It should be noted here that both particle size and lattice 45 strain can contribute to peak broadening in XRD, in particular for nanoparticles. Such lattice strain effects are accounted for by using a modified Scherrer equation ${ }^{38,39}: \beta \cos \theta=\frac{0.89 \lambda}{D}+$ $\eta \sin \theta$, in which $\beta$ is full-width at half-maximum of the XRD peak, $\lambda=1.5418 \AA$ is the incident $\mathrm{x}$-ray wavelength, $\theta$ is the ${ }_{50}$ diffraction angle, and $\mathrm{D}$ is the crystallite size. The latter can then be calculated by a linear fitting of $\beta \cos \theta$ versus $\sin \theta$. For our data, however, we found no dependence of $\beta \cos \theta$ on $\sin \theta$, with data scattering around a fixed value of $\beta \cos \theta$. We take this to indicate the absence of significant lattice strain in 55 our samples, likely due to the high-temperature calcination at $750^{\circ} \mathrm{C}$. Therefore, average particle sizes were calculated directly from the simplified Debye Scherrer equation, i.e.: D $=\frac{0.89 \lambda}{\beta \cos \theta}$.

Figure 4 (B) furthermore shows that the lattice constant 60 changes linearly from $5.41 \AA$ for pure ceria to $5.70 \AA$ for $90 \%$ La content, i.e. an overall increase of more than $5 \%$. This linear increase in lattice constant is in agreement with previous calculations by Morris et al. ${ }^{17}$. However, this is the first time that a verification of these calculations up to high $\mathrm{La}$ ${ }_{65}$ content is possible, since previous attempts using various different synthesis strategies failed to do so due to phase separation of a pure $\mathrm{La}_{2} \mathrm{O}_{3}$ phase at high La contents ${ }^{14,17,19-}$

21 . This highlights the exceptionally well-controlled nature of the reported microemulsion-templated synthesis, which allows 70 formation of mixed oxides across the entire range of $\mathrm{La}: \mathrm{Ce}$ ratios.

The lattice expansion is further confirmed by HR-TEM (Figure 5). Fast Fourier transformation (FFT) analysis of the HR-TEM image was used to identify the (111) plane and 75 measure the lattice parameter of the oxide particles. It shows the expansion of the (111) d-spacing for high La-content mixed oxides from $0.318 \mathrm{~nm}$ for $50 \% \mathrm{La}$ to $0.325 \mathrm{~nm}$ for $90 \%$ La content. For comparison, the value for $\mathrm{CeO}_{2}$ (JCPDS 340394 ) is $0.311 \mathrm{~nm}$ (a comparison to $\mathrm{La}_{2} \mathrm{O}_{3}$ is not possible due 80 to the different crystal structure). This lattice expansion can be attributed to a combination of the effects of increasing number of oxygen vacancies due to La doping and the larger ionic radius of $\mathrm{La}^{3+}$ vs $\mathrm{Ce}^{4+17,37}$. The HR-TEM images thus confirm the highly homogeneous, crystalline structure of these 85 mixed oxides.

In order to further probe the phase stability of the high Lacontent mixed oxides, the samples were calcined at increasingly high temperature and characterized by XRD. Figure 6 shows the development of the XRD pattern for ${ }_{90} \mathrm{La}_{0.9} \mathrm{Ce}_{0.1} \mathrm{O}_{1.55}$ (i.e. $90 \% \mathrm{La}$ ) as a function of calcination temperature ((a) - (c)) in comparison to a pure ceria sample (d). One can see that the sample calcined at $450{ }^{\circ} \mathrm{C}$ shows only broad, weakly defined peaks at $28^{\circ}, 47^{\circ}$ and $53^{\circ}$, which indicates the presence of very small crystallites. With 95 increasing calcination temperature, these peaks get increasingly sharper and well-defined, indicating particle growth as seen before for the pure oxides. However, all diffractograms are in perfect agreement with a shifted fluorite pattern for pure ceria (Figure 6, d). Most significantly, no 100 additional reflections, which would suggest the formation of a separate $\mathrm{La}_{2} \mathrm{O}_{3}$ phase, are observed even after calcination at temperatures as high as $1,050^{\circ} \mathrm{C}$. These results hence further confirm the formation of highly homogeneous mixed oxides, resulting in exceptional phase stability even at such extreme 105 conditions. To our knowledge, this is the first report of such highly stable mixed oxides over a broad range of La contents as high as $90 \%$. 
The exceptional homogeneity and stability of the mixed oxide phase can be attributed to the controlled synthesis. Unlike co-precipitation or non-templated sol-gel methods, the rate of microemulsion-templated syntheses is determined by 5 the diffusion of the precursors from the oil phase into the aqueous phase rather than by precipitation or hydrolysis which tend to be very rapid and hence poorly controlled ${ }^{24}$. The similar diffusivity of the two alkoxide precursors in the oil phase results in similar (effective) reaction rates and hence 10 in well-ordered materials in which the composition on the atomic scale reflects the well-mixed composition of the precursor solution.

However, at this point, we do not have a clear explanation why the mixed oxide phases favor the fluorite crystal structure 15 even for La contents as high as $90 \%$. One possible explanation could be that the amorphous mixed oxide starts crystallizing in the fluorite-type structure during calcination at low temperatures, since the crystallization temperature of ceria $\left(<450^{\circ} \mathrm{C}\right)$ is much lower than that of lanthana $\left(\sim 700^{\circ} \mathrm{C}\right)$, and, 20 once formed, the above discussed homogeneity of the materials results in stabilization this structure. This is supported by the development of the XRD patterns during the crystal growth process of the mixed oxide (see Figure 6). However, more work is required to fully elucidate this point, 25 and particularly computational materials modeling of these mixed oxides could shed further light on this surprising observation.

In addition to crystal structure, the surface area of the mixed oxides is also affected by the La content. Figure 7 30 shows the BET surface area of pure and mixed $\mathrm{La}_{\mathrm{x}} \mathrm{Ce}_{1-\mathrm{x}} \mathrm{O}_{2-0.5 \mathrm{x}}$ oxides vs lanthanum content after calcinations at $450^{\circ} \mathrm{C}$ and $750^{\circ} \mathrm{C}$. At both temperatures, the mixed oxides have significantly higher surface areas than either pure oxide. For example, after calcination at $450^{\circ} \mathrm{C}$ the surface area of ${ }_{35} \mathrm{La}_{0.25} \mathrm{Ce}_{0.75} \mathrm{O}_{1.875}$ is $113 \mathrm{~m}^{2} / \mathrm{g}$, i.e. approximately twice the surface area of pure $\mathrm{La}_{2} \mathrm{O}_{3}$ or pure $\mathrm{CeO}_{2}$. Furthermore, as expected from the results for the pure oxides, the surface area for all samples drops sharply after calcination at $750^{\circ} \mathrm{C}$ for 2 h. For example, the specific surface area of mixed oxides with 40 a La content between $10 \%$ and $50 \%$ drops from $\sim 110 \mathrm{~m}^{2} / \mathrm{g}$ at $450^{\circ} \mathrm{C}$ to $\sim 30 \mathrm{~m}^{2} / \mathrm{g}$ at $750{ }^{\circ} \mathrm{C}$, i.e. the materials lose over $70 \%$ of their surface area. This is consistent with the results for the pure oxides and suggests again that the loss of the residual surfactant capping in this temperature range results in particle 45 growth. However, the mixed oxides still remains roughly twice the surface area of either of the pure oxides. Finally, it is interesting to note that even relatively small La additions to ceria (see $10 \% \mathrm{La}$ in Figure 7) result in a drastic increase in surface area, while the addition of small amounts of $\mathrm{Ce}$ to 50 lanthana (90\% La) has comparatively little impact on the surface area. Clearly, La plays a much more important role in stabilizing high surface areas than Ce.

Beyond surface area, the porosity has a decisive impact on the performance of materials in applications such as sorption, 55 sensing, and catalysis. The pore size distributions of the mixed oxides were hence determined from nitrogen adsorption isotherms using the BJH method. It is worth noticing that the desorption branches of the isotherms of the mixed oxides show a lower closure point at $\mathrm{p} / \mathrm{p}^{0}=0.4 \sim 0.45$, in which case 60 the pore size distribution obtained from the adsorption branch of the isotherm is considered more reliable and was hence used here ${ }^{34,35}$. Figure 8 shows the results for mixed oxide samples with (a) $10 \%$, (b) $25 \%$, (c) $50 \%$, (d) $75 \%$, and (e) $90 \%$ La content. One can see an interesting development of a 65 bimodal pore size distribution as function of La content: The 10\% La sample (Fig, 10 (a)) shows a bimodal distribution with a weak peak at $2.3 \mathrm{~nm}$ ("peak I"), and a more pronounced, broader peak at $12 \mathrm{~nm}$ ("peak II"). Peak I maintains its position at $2.3 \mathrm{~nm}$ for all samples. However, 70 upon increasing the La content to $25 \%$ and $50 \%$, peak II shifts continuously towards lower pore diameters and sharpens noticeably, while at La loadings above $50 \%$, it broadens again and shifts back towards larger pore diameters.

This observation seems to suggest that mixed $\mathrm{La}_{\mathrm{x}} \mathrm{Ce}_{1-\mathrm{x}} \mathrm{O}_{2-\mathrm{x} / 2}$ 75 oxides contain two types of pores, both in the mesopore range. One type of pores has a diameter of $2.3 \mathrm{~nm}$ and appears unaffected by the La:Ce ratio, while the diameter of the second type of pores and its relative contribution to the total pore volume is strongly determined by the La content. ${ }_{80}$ Furthermore, the second type of pores dominates the pattern when the lanthana content is adjusted to either direction away from $50 \%$. While it is tempting to interpret the occurrence of these two types of pores due to the formation of two different oxide phases, this is clearly contradicted by our results from ${ }_{85}$ XRD and TEM investigations, as described above. At this point, we do not have a consistent explanation of this phenomenon. Further investigations appear worthwhile, however, as this suggests a simple way to tailor the pore size for these mixed oxides without a strong impact on surface 90 area (see Figure 7).

\section{Reducibility of pure and mixed oxides}

Finally, the reducibility of the mixed oxides was investigated via $\mathrm{H}_{2}$ temperature programmed reduction. Reducibility and oxygen storage capacity are key functional properties of oxide 95 materials, particularly for ceria which is widely used as oxygen storage and "transfer" agent in catalysis and related applications ${ }^{38,39}$. As discussed before, it can be expected that the reducibility of these mixed oxide samples is strongly affected by the La content due to the introduction of oxygen 100 vacancies.

The TPR patterns are shown in Figure 9 (A), and Table 3 summarizes the respective peak positions, peak areas and $\mathrm{H}_{2}$ consumptions for all samples after calcination at $750^{\circ} \mathrm{C}$. Pure ceria shows a low-temperature reduction peak at $420^{\circ} \mathrm{C}$, 105 which can be attributed to the reduction of surface oxygen, and a high temperature reduction peak above $700^{\circ} \mathrm{C}$, which is due to the (less facile) bulk reduction. In contrast, the mixed oxide with $25 \%$ La content shows only one, broad, strongly enhanced reduction peak, indicating a strong increase in the 110 number of available oxygen species and more easily accessible bulk oxygen. This is in good agreement with the expected effect of La addition, as discussed above. As the $\mathrm{La}$ content increases further, the reduction peak shifts towards lower temperature, indicating increasingly facile reduction of 115 the sample. However, the $\mathrm{H}_{2}$ consumption of the samples with 
$50 \%$ and $75 \%$ La content decreases dramatically (see Table 3 ), indicating a strong decrease in the number of reducible sites.

Table 3 Reduction temperature and hydrogen comsumption

\begin{tabular}{cccc}
\hline & $\begin{array}{c}\text { peak position } \\
\left({ }^{\circ} \mathrm{C}\right)\end{array}$ & $\begin{array}{c}\text { peak area } \\
(\text { a.u. })\end{array}$ & $\begin{array}{c}\mathrm{H}_{2} \text { consumption } \\
(\mu \mathrm{mol} / \mathrm{g})\end{array}$ \\
\hline $\mathrm{CeO}_{2}$ & 420 & 5.12 & 395.5 \\
$\mathrm{La}_{0.25} \mathrm{Ce}_{0.75} \mathrm{O}_{1.875}$ & 500 & 13.36 & 1022.0 \\
$\mathrm{La}_{0.5} \mathrm{Ce}_{0.5} \mathrm{O}_{1.55}$ & 350 & 1.71 & 135.6 \\
$\mathrm{La}_{0.75} \mathrm{Ce}_{0.25} \mathrm{O}_{1.625}$ & 350 & 1.70 & 135.5 \\
$\mathrm{La}_{2} \mathrm{O}_{3}$ & 430 & 1.08 & 88.2 \\
\hline
\end{tabular}

5 The impact of La on the reducibility of ceria was further investigated by X-ray photoelectron spectroscopy (XPS). Figure 9 (B) shows the Ce $3 \mathrm{~d}$ spectra for four different oxide compositions $(0 \%, 25 \%, 50 \%$, and $75 \%$ La). There are 8 peak assignments in the spectra, which are labeled according to the 10 convention established by Burroughs ${ }^{40}$. The peaks U, U', $\mathrm{U}^{\prime \prime}$, and $\mathrm{V}, \mathrm{V}$ ', $\mathrm{V}$,', refer to $3 \mathrm{~d}_{3 / 2}$ and $3 \mathrm{~d}_{5 / 2}$, respectively, and are characteristic of $\mathrm{Ce}^{4+} 3 \mathrm{~d}$ states. The peaks U', V' refer to $3 \mathrm{~d}_{3 / 2}$ and $3 \mathrm{~d}_{5 / 2}$ respectively, and are characteristic of $\mathrm{Ce}^{3+} 3 \mathrm{~d}$ final ${ }^{40}$. The fitted peak contributions and background are 15 indicated by dotted lines for the pure $\mathrm{CeO}_{2}$ sample. The doublets $\mathrm{V}^{0}$ and $\mathrm{U}^{0}$, corresponding to the $\mathrm{Ce}^{3+} 3 \mathrm{~d}^{9} 4 \mathrm{f}^{1} \mathrm{O} 2 \mathrm{p}^{6}$ final state, typically located at 880.6 and $898.9 \mathrm{eV}$, do not appear in our samples, indicating that $\mathrm{Ce}$ is mostly present in the $\mathrm{Ce}^{4+}$ oxidation state ${ }^{41}$.

20 The ratio between $\mathrm{Ce}^{4+}$ and $\mathrm{Ce}^{3+}$ was calculated from the contributions in the XPS spectra, based on the above described peak assignments and the following equations: $\mathrm{Ce}^{4+}=\left(\mathrm{U}+\mathrm{U}^{\prime},+\mathrm{U}{ }^{\prime,},+\mathrm{V}+\mathrm{V}^{\prime}, \mathrm{V}^{\prime},{ }^{\prime}\right) /\left[\sum_{\mathrm{n}},\left(\mathrm{U}^{\mathrm{n}}{ }^{\prime}+\mathrm{V}^{\mathrm{n}}\right)\right](1)$ $\mathrm{Ce}^{3+}=\left(\mathrm{U}^{\prime}+\mathrm{V}^{\prime}\right) /\left[\sum_{\mathrm{n}^{\prime}}\left(\mathrm{U}^{\mathrm{n}}+\mathrm{V}^{\mathrm{n}}\right)\right]$

${ }_{25}$ where $n^{\prime}$ is for all states ${ }^{41}$. Using this method, the fitted peak areas in the XPS spectra were used to estimate the contributions of $\mathrm{Ce}^{4+}$ and $\mathrm{Ce}^{3+}$ as well as sample composition (Table 4). The values obtained for sample composition are in reasonable agreement with the nominally expected values as 30 well as values determined from EDX (cp. Table 2). The difference between the compositions as determined from XPS and the nominal compositions indicates that the surface of the mixed oxide particles are slightly enriched in lanthanum, in particular for low La contents ${ }^{20}$.

${ }_{35}$ Table 4 Atomic composition of samples and their $\mathrm{Ce}^{4+} / \mathrm{Ce}^{3+}$ ratio

\begin{tabular}{cccc}
\hline \multirow{2}{*}{$\mathrm{La} \%$ (nominal) } & \multirow{2}{*}{$\mathrm{Ce}^{4+} / \mathrm{Ce}^{3+}$} & \multicolumn{2}{c}{ Composition by XPS } \\
& & $\mathrm{Ce}$ at. \% & La at. \% \\
\hline 0 & 4.97 & 24.55 & 0.00 \\
25 & 6.47 & 17.82 & 9.15 \\
50 & 7.22 & 13.93 & 18.02 \\
75 & 13.67 & 4.25 & 17.13 \\
\hline
\end{tabular}

More importantly, one can see that the data shows a strong increase in $\mathrm{Ce}^{4+} / \mathrm{Ce}^{3+}$ ratio with increasing La content, from 4.97 for pure $\mathrm{CeO}_{2}$ to 13.67 at $75 \% \mathrm{La}$. This suggests that $\mathrm{La}^{3+}$ is substituting $\mathrm{Ce}^{3+}$ ions in the ceria lattice, hence 40 resulting in an increase of the $\mathrm{Ce}^{4+} / \mathrm{Ce}^{3+}$ ratio. However, since the La amount in all samples exceeds the amount of reduced $\mathrm{Ce}^{3+}$ present in the undoped $\mathrm{CeO}_{2}$ samples (which is $\sim 17 \%$, vs $25 \% \mathrm{La}$ at the lowest La dopings, see Table 4), the La doping results in the formation of additional defects in the oxygen ${ }_{45}$ sublattice along with an increasing shift towards $\mathrm{Ce}^{4+}$ in the Ce content of the samples.
Based on these XPS observations, the TPR results can be understood based on two counter-acting trends with increasing La content: On one hand, the introduction of La increases the 50 defect density in the oxygen sublattice, increasing oxygen mobility and hence the low-temperature reducibility of the mixed oxide. This is also in agreement with previous computational studies by Balducci et al., which show that ceria dopings can lower reduction energies and activation 55 energies of oxygen migration ${ }^{3,15}$. On the other hand, the increasing La content causes a decrease in the absolute number of reducible $\mathrm{Ce}^{4+}$ sites, which results in a decrease in hydrogen consumption in TPR. The interplay between these counter-acting phenomena results in a maximum in the $\mathrm{H}_{2}$ 60 consumption, reflecting an optimal composition for oxidationreduction reactions, and hence indicates that a carefully controlled synthesis of mixed $\mathrm{La} / \mathrm{Ce}$ oxides can result in promising materials for application in catalysis and related reactive applications.

\section{${ }_{65}$ Conclusions}

Pure and mixed cerium and lanthanum oxides are the focus of much interest due to their increasingly wide application in catalysis, absorption and related fields. Hence, there is a need to develop carefully controlled synthesis methods for such 70 mixed oxides, and to establish clear correlations between structure, composition, and activity.

In the present study, we demonstrated the synthesis of mesoporous pure and mixed lanthanum and cerium oxides via a straightforward microemulsion-templated approach, 75 resulting in materials with well-defined nanostructure and surface areas as high as $\sim 110 \mathrm{~m}^{2} / \mathrm{g}$ at $450^{\circ} \mathrm{C}$. Most significantly, the carefully controlled microemulsion environment allowed the synthesis of highly homogeneous mixed $\mathrm{La} / \mathrm{Ce}$-oxides across the entire composition range. ${ }_{80}$ Interestingly, all $\mathrm{La}_{\mathrm{x}} \mathrm{Ce}_{1-\mathrm{x}} \mathrm{O}_{2-0.5 \mathrm{x}}$ crystallize in the fluorite structure of ceria, even for La contents as high as $90 \%$. In addition to structural properties such as lattice parameter and particle size, varying the La content also allows fine tailoring of the reducibility of the samples due to the formation of 85 oxygen vacancies upon incorporation of $\mathrm{La}$ in the ceria lattice.

First results in our laboratory indicate that the described microemulsion-templated synthesis is applicable to a wide range of other mixed oxides, such as $\mathrm{ZrO}_{2}-\mathrm{CeO}_{2}, \mathrm{TiO}_{2}-\mathrm{CeO}_{2}$. The controllable pore size distribution along with tunable 90 reducibility provides a promising avenue for tailored materials for catalysis and separation technology. We are currently extending the described approach beyond tailoring reducibility or oxygen storage capacity towards the introduction of carefully controlled multifunctionality, such as 95 combination of catalytic and adsorptive properties.

\section{Acknowledgement}

This work was supported by the National Energy Technology Laboratory's on-going research under the RDS contract DEAC26-04NT41817; by the Department of Energy - Basic 100 Energy Science through grant DE-FG02-05ER46233; and by the National Science Foundation through grant CTS-0553365. 
G.V. gratefully acknowledges a CNG faculty fellowship of the University of Pittsburgh's Swanson School of Engineering, and a faculty fellowship from DOE-NETL.

\section{Notes and references}

$5{ }^{a}$ US DOE-National Energy Technology Laboratory, Pittsburgh, Pittsburgh, Pennsylvania, United States

${ }^{b}$ Department of Chemical Engineering, 1249 Benedum Hall, University of Pittsburgh, Pittsburgh, Pennsylvania, 15261, United States, Email: gveser@pitt.edu

$10{ }^{c}$ Department of Chemical Engineering, Carnegie Mellon University, Pittsburgh, Pennsylvania 15213, United States

1. Z. G. Yan and C. H. Yan, Journal of Materials Chemistry, 2008, 18, 15 5046-5059.

2. D. Zhang, F. Yoshioka, K. Ikeue and M. Machida, Chemistry of Materials, 2008, 20, 6697-6703.

3. G. Balducci, M. S. Islam, J. Kaspar, P. Fornasiero and M. Graziani, Chemistry of Materials, 2000, 12, 677-681.

20 4. G. Balducci, M. S. Islam, J. Kaspar, P. Fornasiero and M. Graziani, Chemistry of Materials, 2003, 15, 3781-3785.

5. M. Flytzani-Stephanopoulos, M. Sakbodin and Z. Wang, Science, 2006, 312, 1508-1510.

6. Z. Wang and M. Flytzani-Stephanopoulos, Energy \& Fuels, 2005, 19,

$$
25 \text { 2089-2097. }
$$

7. J. R. Chang, S. L. Chang and T. B. Lin, Journal of Catalysis, 1997, 169, 338-346

8. M. Vaarkamp, J. T. Miller, F. S. Modica, G. S. Lane and D. C. Koningsberger, Journal of Catalysis, 1992, 138, 675-685.

30 9. J. G. Nunan, H. J. Robota, M. J. Cohn and S. A. Bradley, Journal of Catalysis, 1992, 133, 309-324.

10. C. de Leitenburg, A. Trovarelli, J. Llorca, F. Cavani and G. Bini, Applied Catalysis A: General, 1996, 139, 161-173.

11. J. Kaspar, P. Fornasiero and M. Graziani, Catalysis Today, 1999, 50, 35 285-298.

12. Q. Fu, A. Weber and M. Flytzani-Stephanopoulos, Catalysis Letters, 2001, 77, 87-95

13. J. B. Park, J. Graciani, J. Evans, D. Stacchiola, S. Ma, P. Liu, A. Nambu, J. F. Sanz, J. Hrbek and J. A. Rodriguez, Proceedings $40 \quad$ of the National Academy of Sciences, 2009, 106, 4975-4980.

14. J. S. Bae, W. K. Choo and C. H. Lee, Journal of the European Ceramic Society, 2004, 24, 1291-1294.

15. G. Balducci, J. Kaspar, P. Fornasiero, M. Graziani and M. S. Islam, The Journal of Physical Chemistry B, 1998, 102, 557-561.

45 16. E. Hosono and S. Kujihara, Chem. Comm., 2004, 2062-2063.

17. B. C. Morris, W. R. Flavell, W. C. Mackrodt and M. A. Morris, Journal of Materials Chemistry, 1993, 3, 1007-1013.

18. V. Belliere, G. Joorst, O. Stephan, F. M. F. de Groot and B. M. Weckhuysen, The Journal of Physical Chemistry B, 2006, 110, 9984-9990.

19. K. M. Ryan, J. P. McGrath, R. A. Farrell, W. M. O. Neill, C. J. Barnes and M. A. Morris, Journal of Physics: Condensed Matter, 2003, L49.

20. M. F. Wilkes, P. Hayden and A. K. Bhattacharya, Journal of 55 Catalysis, 2003, 219, 305-309.
21. S. Dikmen, P. Shuk and M. Greenblatt, Solid State Ionics, 1999, 126, 89-95.

22. M. Fanun, ed., Microemulsions. Properties and Applications., CRC Press, Boca Raton, 2009.

60 23. M. P. Pileni, Langmuir, 1997, 13, 3266-3276.

24. A. J. Zarur and J. Y. Ying, Nature, 2000, 403, 65-67.

25. J. Schicks, D. Neumann, U. Specht and G. Veser, Catalysis Today, 2003, 81, 287-296.

26. M. Kirchhoff, U. Specht and G. Veser, Nanotechnology, 2005, 16, 65 S401-S408.

27. T. Sanders, P. Papas and G. Veser, Chemical Engineering Journal, 2008, 142, 122-132.

28. D. M. Lyons, L. P. Harman and M. A. Morris, Journal of Materials Chemistry, 2004, 14, 1976-1981.

70 29. J. Sheng, S. Zhang, S. Lv and W. Sun, Journal of Materials Science, 2007, 42, 9565-9571.

30. S. Lacombe, C. Geantet and C. Mirodatos, Journal of Catalysis, 1995, 151, 439-452.

31. X. Luo, R. Wang, J. Ni, J. Lin, B. Lin, X. Xu and K. Wei, Catalysis $75 \quad$ Letters, 2009, 133, 382-387.

32. S. Bernal, F. J. Botana, R. García and J. M. Rodríguez-Izquierdo, Reactivity of Solids, 1987, 4, 23-40.

33. G. A. H. Mekhemer and B. A. A. Balboul, Colloids and Surfaces A: Physicochemical and Engineering Aspects, 2001, 181, 19-29.

80 34. K. S. W. Sing, D. H. Everett, R. A. W. Haul, L. Moscou, R. A. Pierotti, J. Rouquerol and T. Siemieniewska, Pure and Applied Chemistry, 1985, 57, 603-619.

35. S. Lowell, J. E. Shields, M. A. Thomas and M. Thommes, Characterization of Porous Solids and Powders: Surface

85 Area, Pore Size and Density, Kluwer Academic Publishers, Dordrecht, 2004.

36. M. D. Fokema and J. Y. Ying, Applied Catalysis B: Environmental, 1998, 18, 71-77.

37. S. Patil, S. Seal, Y. Guo, A. Schulte and J. Norwood, Applied Physics Letters, 2006, 88.

38. G. Dutta, U. V. Waghmare, T. Baidya, M. S. Hegde, K. R. Priolkar and P. R. Sarode, Chemistry of Materials, 2006, 18, 3249.

39. D. Terribile, A. Trovarelli, C. de Leitenburg, G. Dolcetti and J. Llorca, Chemistry of Materials, 1997, 9, 2676-2678.

95 40. P. Burroughs, A. Hamnett, A. F. Orchard and G. Thornton, Journal of the Chemical Society, Dalton Transactions, 1976, 1686-1698.

41. A. Trovarelli, Catalysis by Ceria and Related Materials, World Scientific Publishing 2002. 


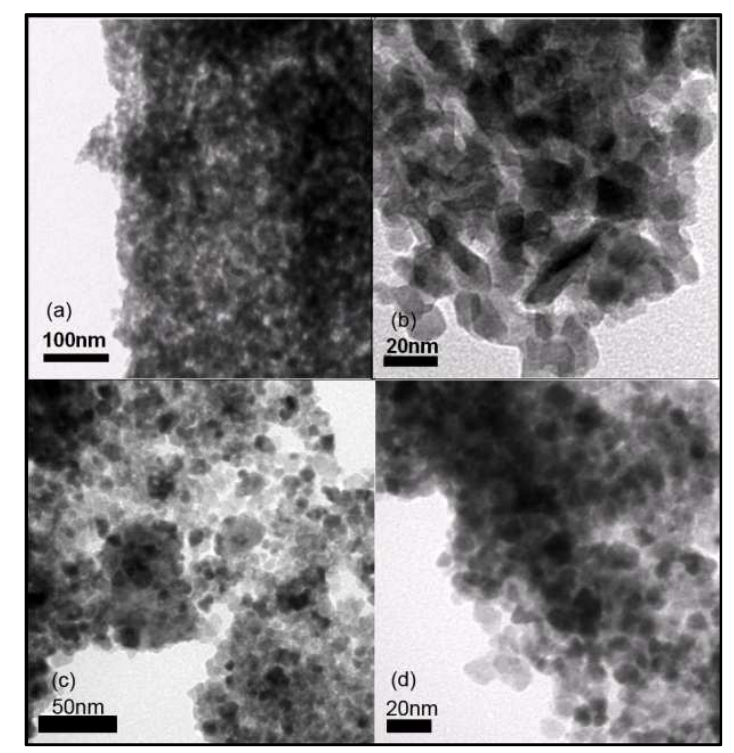

Figure 1 TEM image of crystallized $\mathrm{La}_{2} \mathrm{O}_{3}(\mathrm{a}, \mathrm{b})$ and $\mathrm{CeO}_{2}(\mathrm{c}, \mathrm{d})$, after calcinations at $450^{\circ} \mathrm{C}$ and $750^{\circ} \mathrm{C}$, respectively

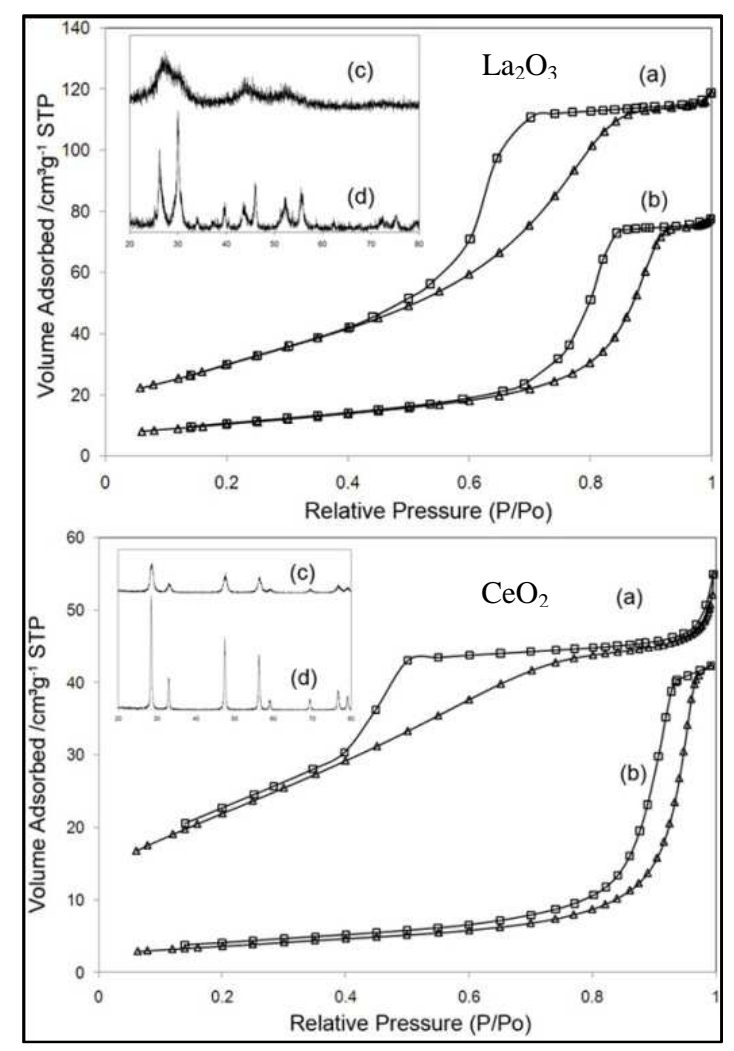

Figure 2 Nitrogen adsorption-desorption isotherms for $\mathrm{La}_{2} \mathrm{O}_{3}$ and $\mathrm{CeO}_{2}$ after calcined at $450{ }^{\circ} \mathrm{C}$ (a) and $750{ }^{\circ} \mathrm{C}(\mathrm{b})$, and XRD diffractograms for $\mathrm{La}_{2} \mathrm{O}_{3}$ and $\mathrm{CeO}_{2}$ after calcined at $450{ }^{\circ} \mathrm{C}(\mathrm{c})$ and $750{ }^{\circ} \mathrm{C}(\mathrm{d})$

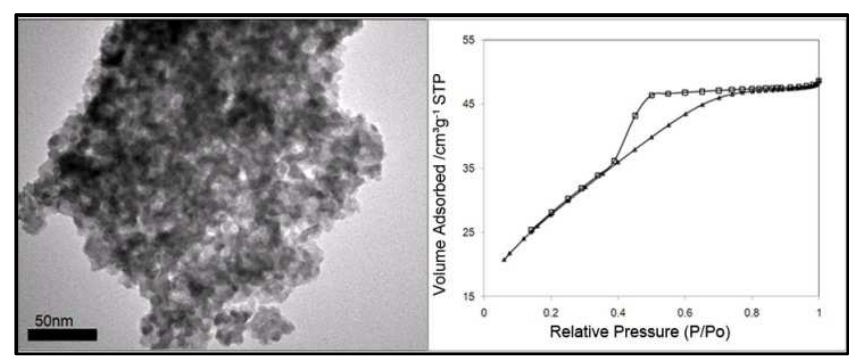

Figure 3 TEM image and Nitrogen adsorption-desorption isotherms for $\mathrm{La}_{0.5} \mathrm{Ce}_{0.5} \mathrm{O}_{1.55}$ calcined at $450^{\circ} \mathrm{C}$.

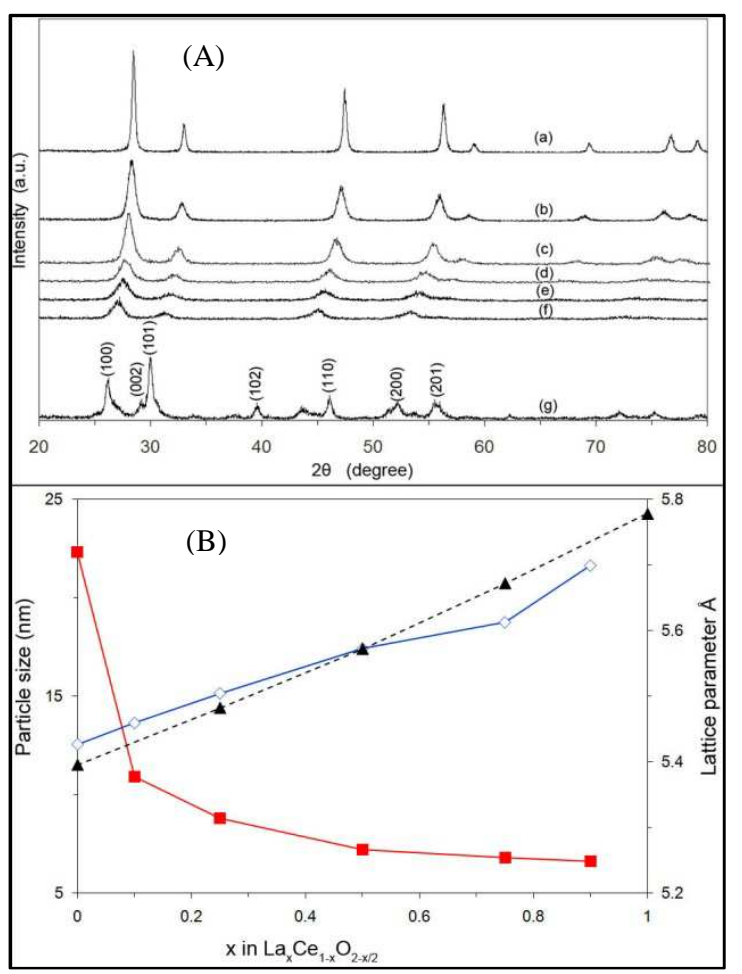

20 Figure 4 (A): XRD of pure and mixed $\mathrm{La}_{\mathrm{x}} \mathrm{Ce}_{1-\mathrm{x}} \mathrm{O}_{2-0.5 \mathrm{x}}$ calcined at $750{ }^{\circ} \mathrm{C}$ with La content (a) $=0 \%$; (b) $=0.1 ;$ (c) $=0.2 ;$ (d) $=0.25 ;$ (e) $=0.5$; (e) $=0.75$; (f) $=0.9 ;(\mathrm{g})=1$, (B): experimental lattice parameter $(\diamond)$, calculated lattice parameter $(\mathbf{A})$, and particle size $(\square)$ of $\mathrm{La}_{x} \mathrm{Ce}_{1-\mathrm{x}} \mathrm{O}_{2-0.5 \mathrm{x}}$ with different La content after calcined at $750^{\circ} \mathrm{C}$.

25

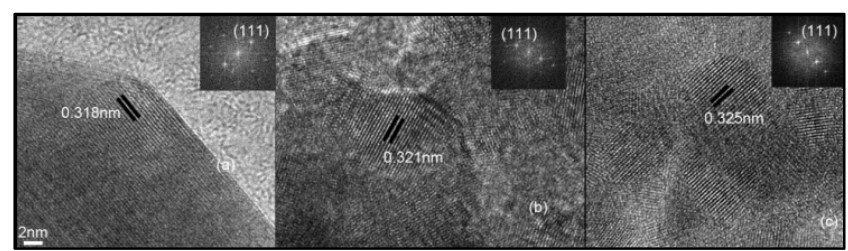

Figure 5 HR-TEM images of $\mathrm{La}_{\mathrm{x}} \mathrm{Ce}_{1-\mathrm{x}} \mathrm{O}_{2-\mathrm{x} / 2}$ with $\mathrm{x}=0.5(\mathrm{a}) ;=0.75$ (b); = 0.9 (c). (Insets show the fast fourier transformation patterns of the 30 respective HR-TEM image). 


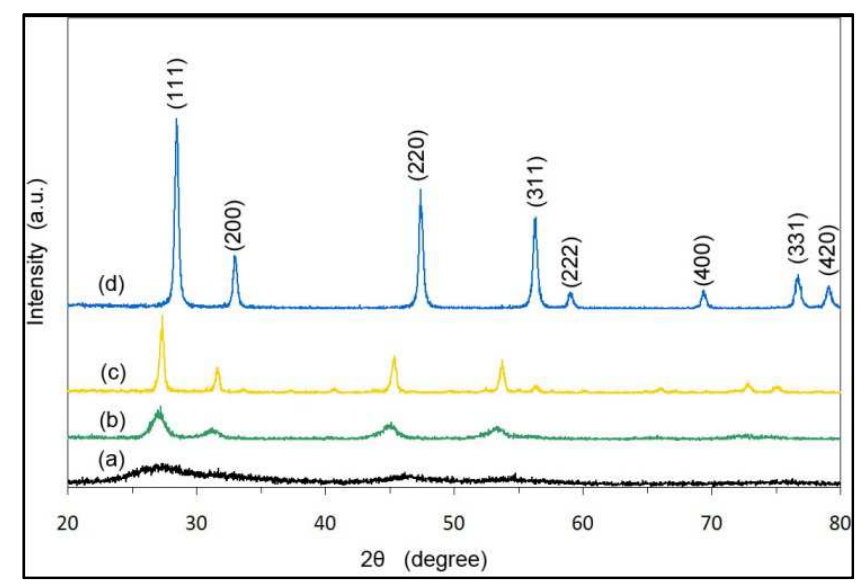

Figure 6 XRD of $\mathrm{La}_{0.9} \mathrm{Ce}_{0.1} \mathrm{O}_{1.55}$ (a) calcined at $450{ }^{\circ} \mathrm{C}$; (b) $750{ }^{\circ} \mathrm{C}$; (c) $1050{ }^{\circ} \mathrm{C}$; (d) $\mathrm{CeO}_{2}$ calcined at $750{ }^{\circ} \mathrm{C}$.

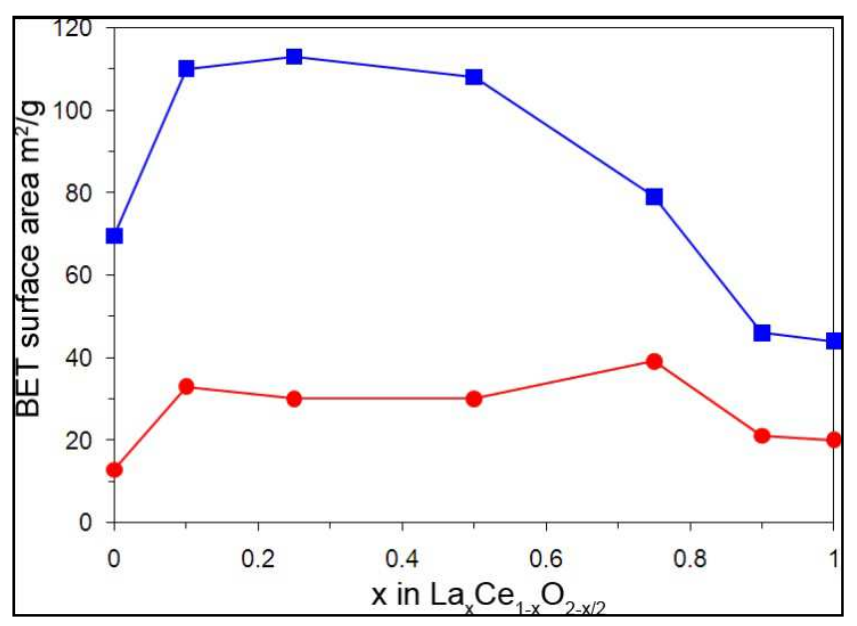

Figure 7 BET surface area of $\mathrm{La}_{\mathrm{x}} \mathrm{Ce}_{1-\mathrm{x}} \mathrm{O}_{2-\mathrm{x} / 2}$ with different lanthanum content, aged at $450{ }^{\circ} \mathrm{C}(\square)$ or $750{ }^{\circ} \mathrm{C}()^{\circ}$.

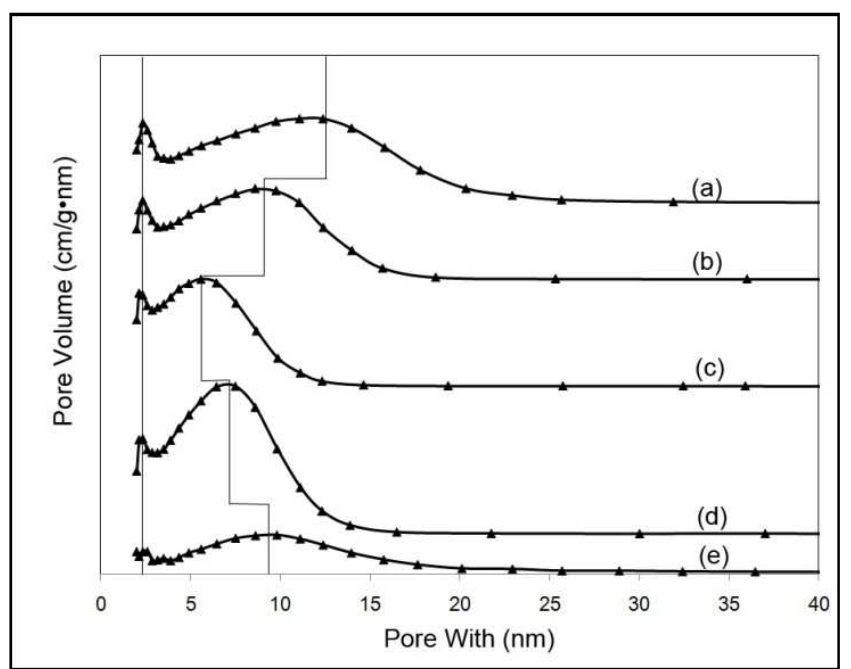

10 Figure 8 BJH pore size distributions obtained from the adsorption branches of the isotherms of $\mathrm{La}_{\mathrm{x}} \mathrm{Ce}_{1-\mathrm{x}} \mathrm{O}_{2-\mathrm{x} / 2}$ with varying $\mathrm{La}$ content after calcinations at $750{ }^{\circ} \mathrm{C}$ for $2 \mathrm{hr}$ in air: (a) $=0.1$; (b) $=0.25$; (c) $=0.5$; (d) $=0.75 ;(\mathrm{e})=0.9$.
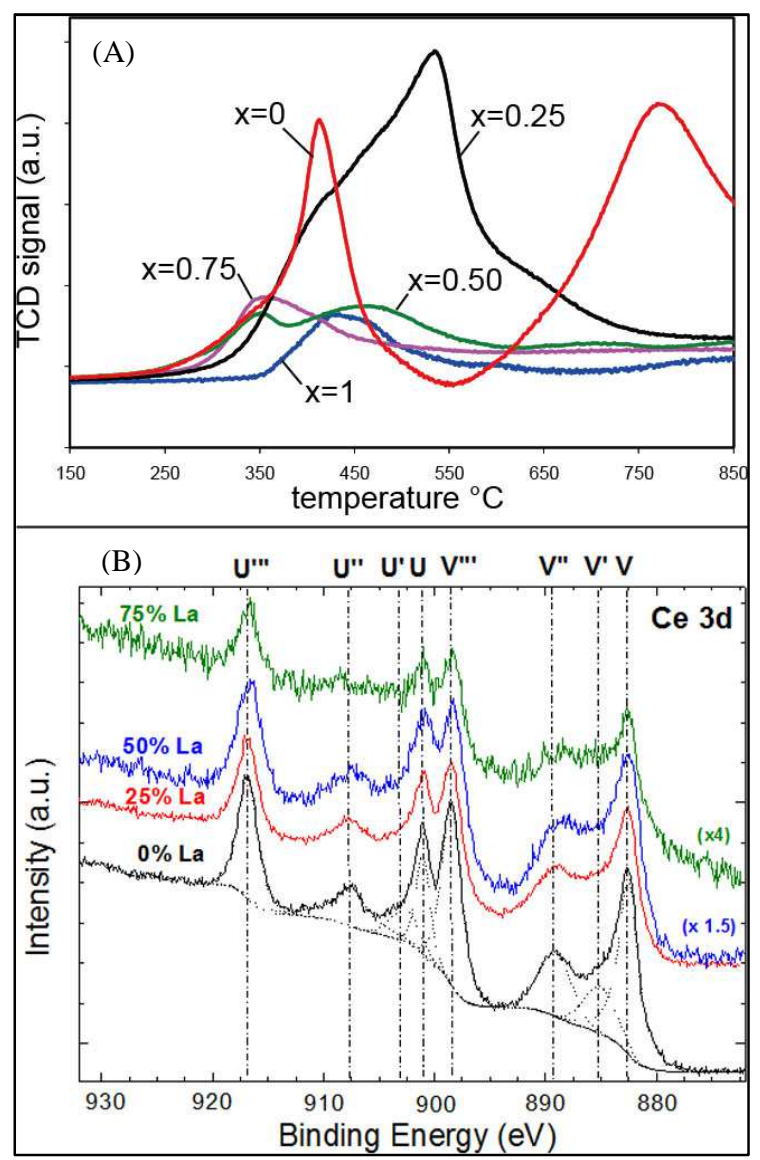

Figure 9 (A) $\mathrm{H}_{2}$-TPR profiles of $\mathrm{La}_{\mathrm{x}} \mathrm{Ce}_{1-\mathrm{x}} \mathrm{O}_{2-\mathrm{x} / 2}$ with different lanthanum content (x), (B) the Ce $3 \mathrm{~d}$ spectra for samples with different amounts of La content. Solid lines represent the experimental spectra and the dotted lines in the $\mathrm{CeO}_{2}$ sample are the Shirley background and the results from 20 peak fitting.

Table Reduction temperature and hydrogen comsumption

\begin{tabular}{cccc}
\hline & $\begin{array}{c}\text { peak position } \\
\left({ }^{\circ} \mathrm{C}\right)\end{array}$ & $\begin{array}{c}\text { peak area } \\
(\text { a.u. })\end{array}$ & $\begin{array}{c}\mathrm{H}_{2} \text { consumption* } \\
(\mu \mathrm{mol} / \mathrm{g})\end{array}$ \\
\hline $\mathrm{CeO}_{2}$ & 420 & 5.12 & $395.5(45)$ \\
$\mathrm{La}_{0.25} \mathrm{Ce}_{0.75} \mathrm{O}_{1.875}$ & 500 & 13.36 & $1022.0(72)$ \\
$\mathrm{La}_{0.5} \mathrm{Ce}_{0.5} \mathrm{O}_{1.55}$ & 350 & 1.71 & $135.6(34)$ \\
$\mathrm{La}_{0.75} \mathrm{Ce}_{0.25} \mathrm{O}_{1.625}$ & 350 & 1.70 & $135.5(34)$ \\
$\mathrm{La}_{2} \mathrm{O}_{3}$ & 430 & 1.08 & $88.2(32)$ \\
\hline
\end{tabular}

* The value in bracket indicates the systematic error. 